\title{
NATURE OF THE SURFACE COMPOUNDS AND REACTIONS OBSERVED ON GRAPHITE ELECTRODES
}

\author{
R. E. PANZER \\ Code 2844, Naval Ship Research and Development Center, Annapolis, \\ Maryland. 21402, U.S.A. \\ and \\ P. J. ELVING \\ Department of Chemistry, Unjversity of Michigan, Ann Arbor, \\ Michigan, 48104, U.S.A.
}

(Received 17 October 1974)

\begin{abstract}
The nature and composition of the surface of pyrolytic graphite and the consequent possible effects, when the material is used as an electrode, are considered on the basis of the structure of the graphite and of the handling and/or treatment to which the electrodes may have been exposed. Because of the relatively limited studies on pyrolytic graphite, certain aspects of the behavior of other types of graphite and of carbon are discussed owing to their probable relation to the behavior of pyrolytic graphite. An appreciation of the constitution of graphite electrodes in terms of surface compounds and of the possible interaction of these compounds with solution species or their reaction products, when the electrodes are used in electrolytic processes, is essential for their optimum utilization. The main areas surveyed are the structure of pyrolytic graphite as related lo electrode usage, types of possible compound formation, electrolytic behavior of graphite electrodes, and formation of carbonoxygen and related organic surface compounds with the resulting influence on adsorption and other phenomena.
\end{abstract}

\section{INTRODUCTION}

Reviews of graphite electrodes, their inherent characteristics, and the reasons for their usage, especially as indicating electrodes in electrochemical studies, have adequately delineated the various types of graphite electrodes currently in use. In the decade since publication of a review[1] on the pyrolytic graphite electrode (pge), it has risen to the forefront among carbon indicating electrodes, although other types and materials such as the carbon paste electrode $[2,3]$ continue to be of interest for specialized techniques and "glassy" or vitreous carbon has become quite common in electrochemical usage [4-7]. However, the application of the various types of carbon electrodes has not been without some "growing pains" from the technical point of view, in particular, the problem of surface compound formation, which is of such great concern to both analytical chemists and electrochemists who use various forms of carbon electrodes.

In the authors' laboratories, the pge is used routinely in stationary and rotating configurations in both aqueous and non-aqueous media, eg, it was used extensively for voltammetric investigations in liquid ammonia in pressurized cells at ambient temperature [8]. Anomalous results obtained with the pge have been attributed to film formation, which may be due to chemisorbed species, oxidation of the carbon, and existence of inherent films or occlusions in the graphitc [9-12]. Some resurfacing techniques may also cause non-reproducible electrode surfaces $[12,13]$. Beilby $[14]$, who investigated the nature of films on the pge, believes that several different surface effects are involved. Beilby's bibliography on carbon and graphite electrodes[15], unfortunately, does not cover carbon anodes used in the chlor-alkali cells, in connection with which fundamental investigations of the oxidation products of carbon formed under electrolytic conditions have been made $[16,17]$.

The present review summarizes experiences in the use of pyrolytic graphite electrodes and approaches the problem of their surfaces from both the chemical and physical viewpoints, $i e$, from the point of view that both the structure and the treatment of the pyrolytic graphite surface will influence the electrode characteristics and behavior of that surface. There are numerous studies concerning the structure of pyrolytic graphite resulting from inclusions and other effects of the gaseous deposition technique used in its production. Brief consideration is given to several pertinent investigations of the high temperature oxidatinn reactions of various forms of carhon; although such reactions may be relatively slow at room temperature, their nature may aid in the elucidation of the oxidation processes involved under other conditions. References dealing with activated carbon and other fincly divided carbons have generally been omitted, chiefly because these materials are so often of questionable purity and because their surfaces are frequently dependent on the history of the starting material used in their manufacture. However, a few papers on such materials have been reviewed, where these present evidence germane to the present discussion, eg, in respect to the organic nature of carbon surfaces.

Recently, the authors[12] investigated the behavior of inorganic and organic species in aqueous and nonaqueous media on pyrolytic graphite and glassy carbon electrodes; factors evaluated include methods of preparation of the graphite, electrode encasement, 
resurfacing methods including magnitudes of the induced electrostatic charge and surface regularity, interplanar adsorption of electroactive solutes, presence of surfactant, acidity, and potential ranges and potential scanning procedures used. Previously, Plock[18] had evaluated the effect of $\mathrm{pH}$ and ligand changes on the usable potential ranges of pyrolytic graphitc, glassy carbon and platinum wire electrodes.

\section{STRUCTURE OF PYROLYTIC GRAPHITE \\ AS RELATED TO ITS ELECTRODE USAGE}

It is at times evident from publications on pyrolytic graphite that some electrochemists are not cognizant of the physical nature of the material. This may be due, at least in part, to the fact that many of the publications on the latter subject are in metallurgical and ceramic journals, eg, the discussion of the technology of pyrolytic graphite preparation and the structure and properties of the product by Lersmacher et al[19] (cf ref. 20).

Pyrolytic graphite is produced by the deposition of carbon from the vapor phase, initially on the surface of a substrate or mandrel. The result is a polycrystalline form of carbon, which is characterized by a high degree of orientation and which shows metallic type behavior in the plane parallel to the surface of deposition ( $a-b$ plane) and ceramic type behavior in the direction perpendicular to the surface of deposition ( $c$ axis), eg, high electrical conductivity in the plane and low conductivity across the plane

Blum and Pappis[21], who concisely summarize physical data on pyrolytic graphite, mention that it is impervious to all gases, including helium, even in films as thin as $0.025 \mathrm{~mm}$, and that it is easily degassed in a vacuum system. Horton [22] noted that pyrolytic graphite has no appreciable pores, as shown by the fact that a very thin cleaved layer, sealed over the end of a glass tube, will maintain a vacuum on the order of $10^{-5}$ Torr.

The structure of any given piece of pyrolytic graphite will be influenced by the mandrel on which it is deposited. Since the mandrel will always contain minute flaws, the deposited carbon tends to reproduce these imperfections, which then serve as nucleation sites for the growth of the cones which are the chief structural characteristic of pyrolytic graphite. Furthermore, particles of foreign matter such as soot and dirt may settle on the growing layers of massive pyrolytic graphite and thus produce discontinuities or nucleation sites for more growth cones. The outcome

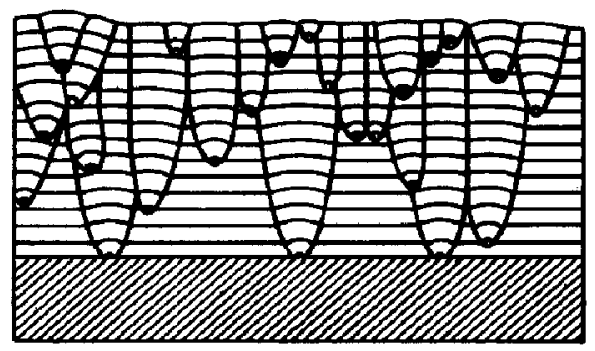

Fig. 1. Schematic representation of pyrolytic graphite structure (taken from General Electric Corp., Pyrolytic Graphite Engineering Handbook, 1963). is that the final structure is one that is continuously nucleated in a random fashion, resulting in grow th cones, mostly microscopic. If the cones are isolated and large in size, they are referred to as nodules; such structures are shown schematically in Fig. 1. Or primary importance to the electrochemist using pyrolytic graphite is the fact that the observed macroscopic surface structure of the material is essentially the same as the microscopically observed pattern, eg, Coy[23] found that subgrains ( $c$ F Fig. 1) of $0 \cdot 1-0.5 \mu \mathrm{m}$ have a very striking resemblance to the structure observed by the eye (a subgrain is one of the nucleated cones on a microscopic scale).

The mechanical and physical properties of pyrolytic graphite have been shown to be closely related to the structure produced during deposition[24]. It would seem reasonable to include the chemical properties, since they are also energy dependent. For example, when pyrolytic graphite is deposited on a male (convex) mandrel, the energy and stresses inherent in the graphite structure are reinforced, while the opposite is true on female (concave) mandrels. Thus, when the pyrolytic graphite is used as an electrode, grinding or cleaving will tend to relieve these stresses, but the released energy may cause more widespread oxidation of the carbons on the edge planes and may enhance the observed surface charges.

\section{Effect of resurfacing}

If the effect of resurfacing a graphite electrode by polishing with 600 mesh $\mathrm{SiC}$ paper is compared to that of resurfacing by cleaving to cxpose a new layer, the latter technique should provide a more reproducible surface. This is essentially because polishing will not only grind the surface flat, but will also cut across the conical deposition planes exposing the vertical edges; it would, consequently, be impossible to reproduce the surface area, stress patterns or grain patterns. Cleavage to a new plane will be at least partly successful in producing similar planes and will not expose the edge planes of each cone step at the surface.

In addition, grinding, which removes carbon by breaking bonds between adjacent atoms and between planes, will break vastly larger numbers of adjacent carbon bonds than cleaving in the case of pyrolytic graphite with its conical structures protruding from the surface. The energy of the bond rupture is partially dissipated as heat, but the surface area is greatly increased and, since all of the surface atoms have unbalanced charges ("free valencies") oriented away from the bulk carbon, the surface energy must similarly be greatly increased. If the grinding is conducted in air, the combination of heat and surface energy provides an environment favorable for oxidation of the carbon by atmospheric oxygen to form a variety of carbon-oxygen compounds ( $c f$ section of Compound Formation).

The effect of mechanical polishing of pyrolytic graphite is discussed by Tarpinian[25], who was naimly concerned with electruchemical polishing and etching of the edge planes. Mechanical polishing of the deposition surface, as mentioned, exposes edge planes when the cones are ground flat; during subsequent electrochemical polishing, pitting occurs on these edges due to the stresses caused by the mechanical scratching. Such etching does not occur on 
electrochemical polishing of an unbroken deposition surface.

The effect of the substrate and the extension of the residual stresses deep into the deposited structure are emphasized by Coffin[24]. Thus, the rougher the structure, the greater the residual stresses and the consequent electrochemical etching when the humps are ground flat, exposing the edge planes. This situation is analogous to that observed when metals are mechanically ground, leaving scratches across grain boundaries; preferential chemical attack, which occurs at grain boundaries, is further enhanced by the mechanical stress at the scratch.

\section{COMPOUND FORMATION}

Much of the behavior of carbon electrodes, which may seem aberrant in nature or productive of artifact phenomena, is likely to be associated with the presence of compounds of varying nature and complexity produced during either preparation of the electrode or its utilization in an electrolytic situation. Thus, it is well known that inleraction of oxygenmeonlaining gases with carbon surfaces produces stable oxygencontaining surface species as well as gaseous products. Because of the often ill-defined, as well as complex, nature of the surface and other possible species, it is difficult to discuss them as systematically as might be desired. In the following subsections, some general aspects of compound formation pertinent to graphite electrodes are reviewed. This is followed by consideration of some aspects of the electrolytic utilization of graphite and related carbon electrodes, and then by a review of the oxidation of carbon surfaces and the nature of the surface species formed. Inevitably, there will be mention of topics which are subsequently discussed in greater detail.

\section{Chemisorption}

The phenomenon of chemisorption, which quite probably plays a distinctive role in the surface effects observed on every type of carbon, may be expected to do so on pyrolytic graphite. There has been no specific investigation of pyrolytic graphite in this regard but relevant information has been obtained on other types of carbon. Walker, Austin and Tietjen[26] when investigating oxygen chemisorption on graphite, found that carhon-oxygen complexes form exclusively at low temperatures (below $200^{\circ} \mathrm{C}$ ); the rate increases with temperature with complex breakdown becoming significant above $500^{\circ} \mathrm{C}$. The role of oxygen-carbon complexes in various processes were investigated, including the behavior of graphite in nuclear reactors; as the latter are brought to operating temperature, the complexes decompose to carbon oxides which then react with the hot steel to carburize it. In situations where the graphite surface is exposed to water vapor, the chemisorbed oxygen provides hydrophilic sites for attracting the water molecules.

Tkach and Davtyan[27] investignted the relation between active centers and the origin of the oxygen potential on carbon. Although their electrode consisted of channel black carbon pressed moist $(50 \mathrm{~kg} /$ $\mathrm{em}^{2}$ ) and then dried under heat and vacuum, the results may be pertinent to the present problem; the qualification arises from the facts that their electrode had an area of $98 \mathrm{~m}^{2} / \mathrm{g}$ (BET method) and finely divided carbons differ from pyrolytic graphite in composition and extent of formation of carbon-oxygen complexes. Davtyan[28] derived a relation between the electrode potential and the quantity of material chemisorbed on the active centers:

$$
E=E_{0}-\frac{E_{0}-E^{\prime}}{\log 2} \log \frac{2 Q_{0}}{Q_{0}+O}
$$

where $E$ is the electrode potential for a given degree of coverage (chemisorbed substance) corresponding to the passage of $Q$ coulombs, $E_{0}$ is the limiting electrode potential in the given solution corresponding to $Q_{0}$ coulombs for saturation coverage, and $E^{\prime}$ is the electrode potential at zero coverage $(Q=0)$. According to this equation, if only active centers are filled during chemisorption, the potential should change regularly to reach a steady value corresponding to the maximum number of active centers per unit surface.

In testing their hypothesis that oxygen is transferred from inactive to active sites on the graphite surface, Tkach and Davtyan! [29] found it necessary to conduct the electrochemical adsorption of the gas very slowly under closely controlled conditions on an electrochemically cleaned electrode. The electrode was first freed of oxygen by cathodically cycling it at various temperatures up to $100^{\circ} \mathrm{C}$ and allowing it to return to its equilibrium potential. In the electrochemical adsorption experiments, the electrode was slowly polarized anodically at various $c d$ and temperatures, to obtain anodic charging curves which were compared with curves calculated from equation 1. They were able to show that oxygen chemisorbed on the surface of a carbon black electrode (catalyst, in their nomenclature) can migrate from inactive to active centers and vice versa in a dynamic equilibrium. Davtyan's equation was confirmed, which supports the argument that the electrode potential is governed not by the total chemisorbed gas but only by its electrochemically (and chemically) active fraction. Confirmation of the number of active centers and of the significant fact that the active centers on the carbon surface, which participate in the chemical oxidation of sulfur dioxide, are also the ones which are electrochemically active, was obtained via a low-temperature oxidation of $\mathrm{SO}_{2}$.

Tkach and Davtyan[29] also established that the mass action law and the formal laws of kinetics do not apply to the oxygen migration process on the carbon black electrode surface. The temperature variation of the rate constants for the migration was determined over a range of $100^{\circ} \mathrm{C}$. The variation of the electrode potential for oxygen coverage of active centers, was only $40 \mathrm{mV}$ for the migration of oxygen on carbon black electrodes, which have a large surface; this indicates that measurement of chemisorbed oxygen on smaller surface areas by Tkach and Davtyan's method might be problematical, if not actually impossible.

\section{Film formation}

Film formation on solid metallic electrodes has been well documented[30-35]; with the increasing use of pyrolytic graphite electrodes, there has been a transfer of the question of film formation as it may occur on this material. 
Miller and Zittel[36] originally claimed that, unlike other solid electrodes used in aqueous solution, residual currents, susceptibility to poisoning and film formation are not problems with pyrolytic graphite and, furthermore, that there was no necessity to treat the pge between successive uses. Later, they and associates[9] reversed these postulations by presenting evidence that a film is formed on pyrolytic graphite which has been oxidized either chemically or electrochemically; the nature of the film was not determined but was believed to be of different character when formed electrochemically.

Several questions arise in considering the latter work. First, the use of a saturated calomel electrode with an asbestos fiber tip in the same cell with the pge may allow a finite amount of readily reducible mercurous ion to enter the working electrode area; secondly, unless extremely good seals are made, solution may seep into the edge exposed planes of the pyrolytic graphite causing erroneous results; finally, soaking the electrode overnight in Ce(IV) solution to form a film may actually allow considerable seepage of solution into the edge planes with subsequent complications when the electrode is used to obtain voltammograms. The problem of sealing the edges of an electrode is a very real one and usually requires sealing of the evacuated edge planes with epoxy cement or with melted polyethylene in situations where epoxy may be attacked by organic solvents.

Turner and Elving[37] reported that the potential range for the pge in pyridine is limited by the oxidation of pyridine or some impurity at ahout $1.4 \mathrm{~V}$ (vs $\mathrm{Ag} / 1 \mathrm{M} \mathrm{AgNO}_{3}$ in pyridine electrode).

Interestingly enough, tetraphenylborate anion $\left(\mathrm{B}\left(\mathrm{C}_{6} \mathrm{H}_{5}\right)_{4}{ }^{-}\right)$, whose oxidation in aqueous media cannot be observed voltammetrically at platinum electrodes due to formation of a film on the platinum[38], gives two well-defined, reproducible twoelectron waves at the pge[39], which have been made the basis of an amperometric titration method for determining potassium[49] and amines[41].

Recent results [12] indicate a possible phenomenon dependent on the surface treatment of the pge. When the pge is resurfaced with 600 mesh SiC paper, the carbon acquires a large positive surface charge (the many layers down into the microstructure may serve as a capacitor), which may lead to the adsorption of anions which, in turn, results in spurious inflections in voltammetric investigations. Additionally, such resurfacing results in a large energy release with attendant oxidation of carbon atoms on the edge planes. Resurfacing by cleavage produces much less surface charge and voltammograms from cleaved surface electrodes were much sharper than those from ground surface electrodes.

As previously mentioned; an alternative electrode material is so called glassy carbon, which has become available in a variety of sizes, shapes and forms, and whose use is becoming widespread[4-7]. It should not be resurfaced except by metallographic polishing techniques, since grinding or other rough treatment was found [12] to drastically increase the surface area with ensuing high residual currents. Glassy carbon does not display any of the surface effects (film formation) seen with pyrolytic graphite and does not require orientation of planes and edge sealing. It is relatively insensitive to changes in $\mathrm{pH}$ and gives bet- ter defined voltammograms of some strong oxidizing agents. Some of the polarographic wave forms taken with glassy carbon electrodes ( $g c e$ ) differ greatly from those from the pge. For example, reduction of $\mathrm{Cu}(\mathrm{II})$ gives two waves at the gce but only one at the pge; the reduction of $U(V I)$ is well defined only on the gce.

\section{Lamellar compounds}

Lamellar compounds are interstitial graphite compounds which retain the characteristic aromatic planar graphite layer structure and which show certain common structural and electrical properties. Generally, a monolayer of the reactant or inserted species is separated by a number of graphite layers, the number depending on the conditions of preparation, in a characteristic distribution. This number, $n$, ie, the ratio of carbon layers to reactant layers, is called the stage of the lamellar compound and is constant throughout the compound for given equilibrium conditions of the external concentration or vapor pressure of the reactant.

The preparation and properties of lamellar compounds involving graphite are described by Hennig[32], eg, the electrical conductivity of such lamellar compounds usually is inuch greater than that of graphite. Of most interest to the present discussion are the lamellar compounds formed as a result of electrolytic oxidation or reduction of the graphite. The only compounds reported formed by electrolytic reduction are amine compounds prepared in liquid atnmonia or amines. Typical compounds have a composition of less than the maximum indicated by $\mathrm{C}_{200} \cdot \mathbf{N H}_{\mathbf{4}}^{+}, 4 \mathbf{N H}_{\mathbf{3}}$; above this ratio, the material decomposes spontaneously[43]. The number of electrolytically formed lamellar compounds is relatively small but they are more stable than non-electrolytic compounds, and the electrolytic reaction can be reversed if an impurity is present which can exchange electrons, eg, water and unreacted carbon can sometimes do this. A typical anodic oxidation reaction is

$$
m \mathrm{C}+3 \mathrm{H}_{2} \mathrm{SO}_{4} \text { (conc.) } \rightarrow \mathrm{C}_{m} \mathrm{HSO}_{4} .2 \mathrm{H}_{2} \mathrm{SO}_{4}
$$$$
+\mathrm{H}^{+}+e^{-}
$$

where $m$ can approach 24 . The method of preparation indicates that these compounds are salt like and ionic in nature, and are, consequently, sometimes designated as graphite salts.

Hennig[42] postulates that any ionic solution species, $\mathbf{M}^{+} \mathbf{X}^{-}$, which is difficult either to reduce or to oxidize, should form electrolytic lamellar compounds at graphite anodes or cathodes:

$$
\begin{aligned}
& \mathrm{C}_{n}+3 \mathrm{M}^{+} \mathrm{X}^{-} \rightarrow \mathrm{C}_{n}^{+} \mathrm{X}^{-} .2 \mathrm{MX}+\mathrm{M}^{+}+e^{-} \\
& \mathrm{C}_{n}+3 \mathrm{M}^{+} \mathrm{X}^{-} \rightarrow \mathrm{C}_{n}^{-} \mathbf{M}^{+} .2 \mathrm{MX}+\mathrm{X}^{-}-e^{-}
\end{aligned}
$$

The invasion of graphite by a lamellar reactant can occur either by concerted attack at all layer planes or by stepwise invasion of a limited number of layer planes, leading to progressively more and more concentrated stages. The second mode is apparently involved in the attack by bisulfate; a very distinct blue color, which only appears late in the reaction, spreads from some peripheral point rapidly across the whole surface, even if the latter is very large. If the reaction were a coneerted attack on all layer planes, the color would be observed at the edges of the crystals from the beginning of the reaction, spreading gradually 
across the crystal surface. The characteristic surface colors observed are usually shades of blue (alkali amine compounds may be purple; alkali metals golden yellow) and sometimes show a quantitative relationship, eg, graphite bisulfate is blue when oxidation has proceeded to the extent of exactly one equivalent per 48 carbon atoms.

The equilibria between the lamellar reactant and carbon in the electrolytic formation of lamellar compounds on graphite can be measured with good precision by determining the electrode potential of the compound. Inflections in the composition-potential curve are observed at concentrations of the reactant on the carbon which correspond to definite compositions.

Another type of lamellar compound, known as an electrolytic lamellar residue compound, results from incomplete remoyal of a lamellar compound, since such compounds are not easily removed when once formed. Complete conversion to the residue compound may not be obtained in some cases, since the reactant may be retained at crystal imperfections where bonding due to free valencies may be very strong[42].

Recently, Besenhard and Fritz[44] produced electrolytic lamellar compounds of graphite with welldefined oxidation steps. By using fluoroborate, hexafluorophosphate, hexafluoroarsenate and perchlorate electrolytes in propylene carbonate, nitromethane or acetonitrile media, salt-like compounds of the type $C_{n} X$ were formed where $n=24$.

\section{ELECTROLYTIC BEHAVIOR}

This section is concerned with electrolytic behavior and reactions involving the more massive forms of carbon, eg, common graphite, wax-impregnated graphite, colloidal carbon deposited on a substrate, and pyrolytic graphite. The reactions and products formed are as varied as the forms of carbon themselves.

The differential capacity of pyrolytic graphite electrodes has been examined in aqueous media $[45,46]$ and in pyridine[45]. The strong influence of surface roughness of solid electrodes on electrochemical measurements has been critically examined from the theoretical viewpoint by de Levie $[47,48]$.

\section{Oxidation reactions on carbon electrodes}

Bulygin[49], who investigated the destruction of graphite electrodes in various alkali or oxyacid solutions where only oxygen is liberated, observed chemical (gassing of $\mathrm{CO}_{2}$ and $\mathrm{O}_{2}$ ) and mechanical (spallation) losses at temperatures from $30^{\circ}$ to $90^{\circ} \mathrm{C}$ for $c d$ (apparent) of $200-3000 \mathrm{~A} / \mathrm{m}^{2}$. The higher chemical losses observed in acidic solution, which are independent of the specific character of the anion, were ascribed to the oxygen liberated in these solutions being a more active oxjdizing agent than that formed in alkaline solution. Furthermore, oxidation of graphite in acid solution gives pyromellitic acid and intermediate surface oxides, processes which evidently have lower activation energies than that for formation of the final product, $\mathrm{CO}_{2}$.

In a comparison [50] of the performance of pyrolytic graphite electrodes with that reported for the waximpregnated carbon electrode[51], reactions seemed to be more reversible on the pge, but results obtained with low-temperature prepared pge film electrodes varied from those obtained with massive pge electrodes, indicating differences in their nature. This behavior parallels that of the behavior of the surface of metals, which, sometimes considered to be simpler than that of carbon surfaces, has been shown by improved techniques and instrumentation to be more complicated than first thought [52].

Binder et al[53] used various forms of finely divided carbon, including soot, charcoal and graphite, which werc compacted into massive electrodes, to investigate their oxidation when made anodic in solutions of oxyacids and $\mathrm{KOH}$. Although their $c d$ values scem somewhat empirical, they found that, below the reversible potential of oxygen, the carbon oxidized formed $80 \% \mathrm{CO}_{2}$ and $20 \%$ of a carbon-oxygen compound, which was not identified but which was thermally stable above $130^{\circ} \mathrm{C}$; only a minor portion of it could be reduced. This reducible portion was postulated to be an oxide surface layer, such that every ninth carbon atom carried a unit charge. The surface laycr may also contain some non-reducible oxide, since oxygen was found to be incorporated in the electrode carbon in quantities up to 0.4 formula weight/mole. Based on this assumption and that of homogeneous distribution of the oxide, every third carbon atom would formally carry a unit charge, ie, the atomic ratio of $C$ to $O$ would be $6: 1[53]$.

Yeager, Krouse and Rao[54], who wanted to study the effect of pressure on potential and to develop a cell usable to $100 \mathrm{~atm}$, used the pge in $\mathrm{KOH}$ solution prepared with great care using conductivity water. (However, they questioned whether such precautions are justifiable, since electrode purity and reproducibility of clectrode surface are subject to such variations.) Polished pyrolytic graphite showed pits; further polishing turned up more pits. Under the experimental conditions, reproducible data were obtained only for paraffin-filled graphite used either anodic or cathodic. The authors questioned whether the same surface conditions obtained at both anode and cathode, and were at a loss to explain the results of the anodic polarization. However, carrying a carbon electrode to extreme anodic voltages is known to produce irreversible changes and it is this which may have led to the anomalous results. Perhaps Vignaud's observation[ 10$]$ that the carbon electrode behaves like a mixed electrode is more a fact than a postulation.

\section{Chlor-alkali electrolysis}

Heller[16] extensively investigated the nature of the blue color produced in $\mathrm{NaOH}$ during electrolysis of brine with graphite anodes; this coloration is objectionable to users of the $\mathrm{NaOH}$ and great effort has been made to eliminate it from the final product. Heller found that, instead of being due to iron contamination and complex formation as had been commonly supposed, the color was apparently duc to a pyromellitic acid-chloroquinol of formula $\mathrm{C}_{10} \mathrm{H}_{5} \mathrm{O}_{3} \mathrm{Cl}$ (presumed structure is $\mathrm{I}$ in Fig. 2). It is yellow in neutral aqueous solution and is very stable, $e g$, it is not destroyed by aqua regia or mixed nitricsulfuric acids. It is easily reduced in alkaline solution to give a red solution (Fig. 2) and is just as readily reoxidized (even by shaking the solution in contact with air). When fused with $\mathrm{NaOH}$, it gives compound 


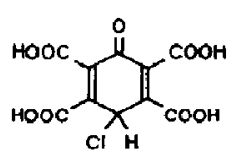

I

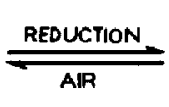

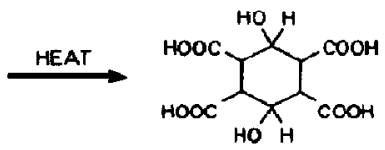

III

Fig. 2. Presumed reactions and structure of compound $\mathrm{C}_{10} \mathrm{H}_{5} \mathrm{O}_{9} \mathrm{Cl}$ (I) produced at the graphite anode in chlor-alkali electrolysis cell[16]. Colors: I, yellow; II, red; III, blue.

III of Fig. 2. The compound reacts with $z$-naphthol in a manner similar to pyromellitic acid.

Later work[55] on the effects of anode material and operating variables on the caustic color produced verified the reactions of the pyromellitic compound described by Heller[16]. Significantly, it was observed that (a) non-graphite electrodes, eg, platinum, do not give the blue color, (b) spectrographic purification of the graphite does not decrease the amount of color, and (c) the color intensity is proportional to the rate of attack on the graphite. Chemical oxidation is an important factor in production of the colored pyromellitic derivative, eg, it was also produced by oxidation of graphite particles in hypochlorite solutions. The characteristic red-brown coloration of the pyromellitic reduction product was readily observed on treatment of unconcentrated caustic cell effluent with a reducing agent such as dithionite. Materials of lesser graphitic structure gave increased color concentration in the cell effluent, indicating that smaller crystal size and greater surface area aid production of the pyromellitic species.

Wawzonek and Eftax [17] questioned Heller's characterization of the color compound, mainly because dienones, in which a hydrogen is involved, are unknown since they would easily rearrange to phenols. Wawzonek and Eftax isolated from stubs of chloralkali cell graphite anodes a yellow solid, which contained mellitic acid, pentacarboxychlorobenzene, a tetracarboxychlorobenzene of unknown configuration, and a compound of unknown structure which is the source of the blue color. Some of the compounds isolated were dark colored tars and oils, which colored the caustic cell effluent; due to their much higher molecular weight, thcy arc morc complex than the compound proposed by Heller. Heller's technique of recrystallizing from nitric acid the mixture extracted from the anode stubs apparently served to degrade the original compounds.

Heller[16] also noted some evidence that the presence of sulfate increased oxidation of graphite and production of colored compounds, and that extracts of the anode stubs from chlor-alkali cells contained a higher proportion of sodium sulfate than did the original brine fed to the cell. (It should be noted that one method for production of pyromellitic is by sulfuric acid oxidation of carbon.) Along the same line of investigation, the presence of sulfate in the brine solutions was found[56] to strongly increase the corrosion of graphite anodes; it was consequently suggested that specific adsorption of sulfate on the graphite with the resultant swelling of the graphite caused the increased corrosion. This hypothesis was verified through the use of radioactive tracers by Flisskij et al.[57], who proposed that the specific adsorption of sulfate ions on carbon tends to increase the anode potential in the same way that certain anions, eg. fluoride, cyanide and thiocyanate, do on platinum electrodes. The resulting higher activity of atomic oxygen would produce increased oxidation of the graphite anode, particularly of its outer surface. Actually, the presence of sulfate does indeed produce effects which may be of major importance in the use of pyrolytic graphite electrodes[9].

Pertinent to the preceding discussion are studies of the anodic degradation of electrographic materials in saturated brine and concentrated oxyacid electrolyte solutions, using both light and electron microscopy to follow the progressive attack on the graphite surface [58]. The rate of wear in the oxyacid solutions could be correlated with the relative tendency to form graphite intercalation compounds. Also relevant are such investigations as those of the kinctics and mechanisms of the electrochemical oxidation of graphite anodes in bisulphate melts[59] and of the surface nature and oxidation of graphite anodes during the electrolysis of acidic $\mathrm{NaCl}$ solutions[60].

\section{Oxygen electrodes}

From the electrochemical standpoint, it is notable that the only known ręversible oxygen gas electrode at room temperature involves carbon as the conducting solid and requires the presence of $\mathrm{OH}^{-}$and $\mathrm{HO}_{2}^{-}$ in solution. There is some evidence that the oxygen involved may be adsorbed as a peroxidic complex $\left(\mathrm{C}_{y} \mathrm{O}_{2}\right)[61]$. The electrode reaction is probably as follows:

$$
\begin{gathered}
\left(\mathrm{C}_{y}\right)+\mathrm{O}_{2} \rightleftharpoons\left(\mathrm{C}_{y} \mathrm{O}_{2}\right) \\
\left(\mathrm{C}_{y} \mathrm{O}_{2}\right)+\mathrm{H}_{2} \mathrm{O}+2 e^{-} \rightleftharpoons\left(\mathrm{C}_{y}\right)+\mathrm{HO}_{2}^{-}+\mathrm{OH}
\end{gathered}
$$

It seems likely that the second reaction is composed of two one-electron steps involving an adsorbed $\left(\mathbf{H} \dot{\mathrm{O}}_{2}\right)$ radical as an intermediate. In this respect, the mechanism is similar to the one proposed by Garten and Fppinger[62] for the production of hydrogen peroxide when air (oxygen) and acid are available to the surface $\mathrm{C}-\mathrm{O}$ complexes:

$$
\begin{aligned}
\left(\mathrm{C}_{v} \mathrm{O}_{2}\right)+\mathrm{H}_{3} \mathrm{O}^{+}+A^{-} \longrightarrow\left(\mathrm{C}_{v} \mathrm{OH}\right)^{+} & \\
+A^{-} & +\mathrm{H}_{2} \mathrm{O}_{2}
\end{aligned}
$$

However, carbons suitable for a reversible electrode are massive pieces, which do not have the area to show such other cffects as are observed in peroxide production on powder-type electrodes having a higher density of reaction sites.

Garten and Weiss[63] have ably reviewed the ionand electron-exchange properties of activated carbon in relation to its behavior as a catalyst and adsorbent. Activated carbon, whose name is really a misnomer, since it should be considered as a complex polymer and not as an amorphous form of carbon, usually contains from 2 to $25 \%$ oxygen and considerable quantities of hydrogen, and differs from other polymers in its large surface area (up to $2500 \mathrm{~m}^{2} / \mathrm{g}$ ) 

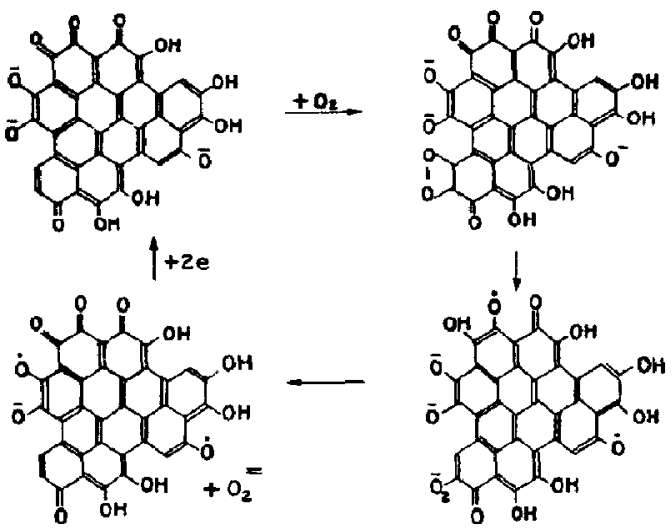

Fig. 3. Catalytic mechanism proposed[63] to explain the functioning of a carbon surface as an oxygen electrode.

and in being a good electrical conductor; these facts help to explain its catalytic activity. When such a carbon is used as ath oxygen electrode, the olefinic bonds of the carben atoms associated with quinone groups add molecular oxygen to form a hydroperoxide or moloxide (molecular oxide), which accepts an electron to form the monovalent peroxide anion radical which may remain attached to the carbon by virtue of the ability of the quinone to form a semiquinone after addition of a second electron; the reduced oxygen molecule splits off as the peroxide anion. This catalytic mechanism involving the anion depends on the carbon atoms forming semiquinones, which can occur to an appreciable extent only under alkaline conditions, thus accounting for the fact that reasonable currents can be drawn only under such conditions. 'I'his mechanism is shown schematically in Fig. 3.

Bulawa[64] found that powdered carbons made from oxidation of sugar at temperatures up to $1000^{\circ} \mathrm{C}$ could be used as gas-carbon electrodes when the gas contacted the complex carbon oxygen groupings on the surface. When acidic groups were present, the material was most suitable for an oxygen electrode, while the presence of basic groups (carbon with basic properties) was best for a chlorine electrode.

\section{Quinhydrone electrode behavior}

In light of the previous and subscquent discussion concerning the existence of quinone, semiquinone and hydroquinone functionalities on carbon, the general behavior of the quinone-hydroquinone half-reaction (quinhydrone system) at graphite and other carbon electrodes is summarized:

$$
\mathrm{Q}+2 \mathrm{H}^{+}+2 \mathrm{c} \rightleftharpoons \mathrm{H}_{2} \mathrm{Q}
$$

Morris and Schemp[65], who used voltammetry in unstirred aqueous solution at wax-impregnated spectroscopic graphite electrodes, reported that the quinhydrone system behaved irreversibly, producing two waves, whose $E_{p / 2}$ values become more negative for the reduction of quinone and more positive for the oxidation of hydroquinone from $\mathrm{pH} 1-7$. Their analysis indicated that each wave involved only a one-electron process, probably due to semiquinone formation; this behavior is in strong contrast to that at the dropping mercury electrode, where a reversible two-electron reaction occurs.
Turner and Elving $\lfloor 66\rfloor$, who investigated the electrochemical behavior of quinone, hydroquinone and quinhydrone in pyridine medium at the stationary pge, found the reduction of quinone to be a reversible one-electron process to the free radical anion and the oxidation of hydroquinone to be an irreversible two-elcctron process involving the solvent; quinhydrone behaves as a mixture of quinone and hydroquinone, the potentials of whose waves are $0.5 \mathrm{~V}$ apart. More reproducible cyclic voltammograms were obtained for quinone in pyridine at cleaved pyrolytic graphite electrodes than at electrodes resurfaced by grinding [12].

One wonders if the structure of the graphite layers (almost identical with the hexagonal lattice of quinone and hydroquinone) might not be affecting the quinone-hydroquinone system by tying up the hydroquinone in some manner; the observation by Boehm et al $[67,68]$ of hydroquinone and quinone groups on carbon preparations lends some credence to this idea, which should be investigated.

In this connection, it should be noted that Blurton[69] ascribed the cyclic voltammetric anodic and cathodic peaks seen with carbon electrodes in acidic media to oxidation of hydroquinone groups and reduction of quinone groups on the carbon, respectively. Treating colloidal graphite on a Dacron substrate with various triphenylmethane dyes of the quinone and semiquinone types, produced an ionexchange surface on the carbon particles, whose cation activity was increased when the carbon was chemically oxidized[70].

Janz and Ives[71] present a lengthy discussion on the preparation of the quinhydrone electrode and its relation to the metal phase of the electrode. It would seem that the use of carbon would eliminate some of the problems of metal surface preparation, including the general problems of oxide layers, cleanliness and alloy usage. However, one may be trading one problem for another in light of the irreversibility of the quinhydrone system observed at carbon electrodes. On the other hand, the irreversibility observed for the quinone-hydroquinone system is not a general characteristic of the pge. For example, the nitrosobenzene-phenylhydroxylamine couple behaves reversibly at the pge in aqueous $50 \%$ ethanol solution over the $\mathrm{pH}$ range from 1.6 to above 8 , where the phenylhydroxylamine is chemically oxidized[72]. The potentials obtained agree with those measured potentiometrically at platinum electrodes and polarographically at mercury electrodes.

\section{SURFACE COMPOUND FORMATION}

Although it is difficult to formulate a precise definition of surface compounds on carbon (related to stoichiometric compositions), it is perhaps helpful to begin with that of Smith, whose review [73] is concerned with carbon having $20 \%$ or less oxygen attached, since the most important surface compounds are those initially produced by interaction of oxygen with the aromatic carbon graphite surface. This limit eliminates such compounds as mellitic anhydride, carbon suboxide and graphite oxide, which are solids with reasonably well defined properties. On the other hand, the low concentration of carbonoxygen compounds present on every carbon surface 
used in the laboratory and in commerce is the source of many observed phenomena and is the reason for the usefulness of carbon materials for rubber compounding, lubrication, etc.

As previously mentioned, discussion of papers concerning the character of activated and other finely divided carbons has been essentially omitted as not germane to the objective of the present review. However, in this section a few papers are reviewed, which present evidence on the oxidized, in particular, organic, nature of carbon surfaces. It should be emphasized that some of the work to be cited does not ahsolutely prove the existence of the hypothesized compounds or that, at best the proof is sketchy.

In connection with the surface oxidation of carbon and the surface carbon-oxygen complexes formed, the limits of the temperature ranges often designated as "high" and "low" may be somewhat arbitrarily set at $200-500^{\circ} \mathrm{C}$ for the low range and from $550^{\circ} \mathrm{C}$ upward for the high range. The review by Culver and Watts[74] of the structure of carbon and of the chemisorption and physical characteristics of charcoals and carbon blacks, as related to the interaction of gases with the surfaces of finely divided carbon, is typical of many on these topics.

Typical of investigations of the behavior of graphite anodes, in which attempts are made to characterize the formation of carbon-oxygen surface species, is that of the kinetics of the anodic reaction in the electrolysis of molten nitrates[75].

\section{Oxidation sites}

It has been indicated that the edge atoms of the carbon planes in the pyrolytic graphite structure would be most reactive because of the residual valence bonds and that reactions would thus occur preferentially in a direction perpendicular to the cones. Contrary to this expectation, Levy[76] found that pyrolytic graphite oxidized preferentially on the $c$ planes, rather than on the edge-wise $a b$ planes. Consequently, localized regions in the pyrolytic graphite planes appear to have stresses depending on the degree of curvature of the conical sections. The energy associated with these localized strained areas may then favor oxidation. Nevertheless, pyrolytic graphite does not oxidize as rapidly as ordinary graphite until a temperature of about $800^{\circ} \mathrm{C}$ is reached. In a subsequent study[77], Levy and Wong claim that oxidation of pyrolytic graphite occurs preferentially in the $a$ direction.

In a study [22] of the oxidation kinetics of pyrolytic graphite in the range of $614^{\circ}$ to $1568^{\circ} \mathrm{C}$ the maximum levels of most light and many heavy metals (determined by the sensitivity of the analytical methods used) uas less than $0.01 \%$, while some, $e g, \mathrm{Ca}, \mathrm{P}, \mathrm{Pb}$, $\mathrm{Ba}$ and $\mathrm{Na}$, were in the range of $0.01-0.2 \%$. These figures are important, since catalytic effects due to foreign substances in the pyrolytic graphite layers make important contributions to its reactivity. Horton[22] proposed that the following reactions occur, forming reactive sites on the carbon surface:

$$
\begin{gathered}
\mathrm{C}(g r)+\mathrm{O}_{2}(g) \rightarrow \mathrm{C}-\mathrm{O}(\text { sites })(s) \\
\mathrm{C}-\mathrm{O}(\text { sites })(s) \rightarrow \mathrm{CO}(g) \text { and } \mathrm{CO}_{2}(g)
\end{gathered}
$$

The overall reaction rate is proportional to the concentration of $\mathrm{C}-\mathrm{O}$ sites formed, which, in turn, is pro- portional to the square root of the partial pressure of $\mathrm{O}_{2}$ or of its concentration on the surface.

Supplementary to the previous study is the gravimetric study of the oxidation kinetics of pyrolytic graphite between $677^{\circ}$ and $1010^{\circ} \mathrm{C}$ at air velocities of $25-100 \mathrm{~cm} / \mathrm{s}$ and atmospheric pressure[77].

In an investigation[78] of the oxidation of carbons and graphite by oxygen, using electron microscopy to detect and follow reaction effects, pyrolytic graphite, unlike natural single crystal graphite, showed only a general overall eroding of the surface. Hexagonal pits were formed at the sites of natural single crystal graphite. where inclusions of iron catalyzed the oxjdation. The authors, along with others who have studied similar catalyzed oxidations, noted that the purities of graphite are only relative and that only a few foreign atoms per billion carbon atoms are sufficient to catalyze the reactions. Hennig's results[79] on the oxidation of single crystal graphite indicate that "zigzag edges" are present on carbon oxidized by moist oxygen.

A microscopic study of graphite oxidation[17] contains beautiful optical and electron photomicrographs of etch pits, etc, some of which were made at $900^{\circ} \mathrm{C}$ on a microscope hot stage. Although much of the work rcportcd is at $870-900^{\circ} \mathrm{C}$, using $\mathrm{O}_{2}, \mathrm{NO}$ or $\mathrm{CO}_{2}$ atmospheres, it is notable that, with atomic oxygen at $200^{\circ} \mathrm{C}$, oxidation, etch pits and general removal of carbon occurred on the $a-b$ planes of the pyrolytic graphite. The effects of such catalyst particles as $\mathrm{Ni}$, $\mathrm{Co}, \mathrm{Mn}, \mathrm{Ta}, \mathrm{Ti}, \mathrm{Ag}, \mathrm{Mo}$ and $\mathrm{B}$ at $720^{\circ} \mathrm{C}$ and higher temperatures were also investigated.

The surface reactions of oxygen on single crystals of natural graphite, which had been purified by acid treatment and heated to $3000^{\circ} \mathrm{C}$, were investigated at temperatures below $1000^{\circ} \mathrm{C}$ and under an oxygen pressure of $10^{-3}$ to $1 \mathrm{~atm}$. The carbon-oxygen reaction is apparently half-order under all conditions studied, but, if the crystals are preheated, they are oxidized more rapidly. This behavior was traced to the presence of very tenaciously held water, which catalyzes the oxidation, produced whenever the sample was exposed to water at room temperature or higher, with or without oxygen being present. The tenacity, with which water is held, was determined by adsorbing tritiated water on the graphite and heating for various times at different temperatures (Table 1). Although the catalytic effect of water can be suppressed by adding chlorine to the oxygen stream, this

Table 1. Retention of adsorbed water on graphite*

\begin{tabular}{ccc}
\hline $\begin{array}{l}\text { Heat treatment } \\
\text { Temp. } \\
(\mathrm{C})\end{array}$ & $\begin{array}{c}\text { Time } \\
\text { (min) })\end{array}$ & $\begin{array}{c}\text { Fraction } \\
\text { water } \\
\text { retained }\end{array}$ \\
\hline 300 & 25 & 0.743 \\
400 & 10 & 0.655 \\
500 & 20 & 0.370 \\
600 & 35 & 0.167 \\
700 & 5 & 0.161 \\
800 & 20 & 0.090 \\
900 & 10 & 0.068 \\
1000 & 15 & 0.044 \\
1100 & 25 & 0.015 \\
1200 & 15 & 0.005 \\
\hline
\end{tabular}

* Taken from Hennig[90] 


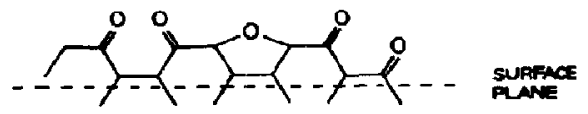

A B C

Fig. 4. Postulated structure of surface oxide configuration on graphite[80].

causes conversion of surface steps in the structure to slopes. There was also inhibition of the catalytic effect of water by $\mathrm{SiO}_{2}$ and $\mathrm{SiC}$ from quartz containers used in the experiments but not with platinum containers. Various contaminants cause channeling of the carbon and catalyze the oxidation of carbon due to localization of the catalyst particles in the carbon at lattice defects.

Hennig[80], who has discussed the structures of surface oxide compounds, a surprisingly large amount of which is formed on the reaction of oxygen with graphite, has postulated the existence of several types of surface oxides (Fig. 4). The $B$ type is thought to be most reactive in forming volatile products, while the $C$ type is not present in large concentration.

Since the oxygen is bound to carbon which was (at least originally) part of an aromatic ring system, it is apparent that organic functionalities are generated as the result of the surface oxidation.

For example, Garten and Eppinger[62] present voluminous data on surface areas, reduction of $\mathrm{H}_{2} \mathrm{O}_{2}$ and reaction mechanisms for carbon blacks heated in air. Some reduce hydrogen peroxide on exposure to acid and air; on the other hand, only a very small amount of peroxide is formed (maximum of $80 \mu-$ equiv/mole of carbon) when heated to $900^{\circ} \mathrm{C}$ in air with an acid present. However, optimum reaction to form the various oxidation products occurs below $550^{\circ} \mathrm{C}$. The evidence presented lends some credence to the existence of phenol, lactone and chromene groups on carbon blacks.

\section{Organic functionalities}

Although Smith's review [73] is mostly concerned with carbon blacks or finely divided materials, it contains much valuable background information concerning the nature of the surface compounds observed on graphite electrodes. Temperature, as expected, is the most important factor in complex formation with oxidizing gases, eg, the optimum temperature range for reaction with $\mathrm{O}_{2}$ or $\mathrm{NO}_{2}$ is $400-500^{\circ} \mathrm{C}$ but ozone reacts at room temperature, producing products with up to $20 \%$ oxygen ( $c$ reaction with atomic oxygen at $200^{\circ} \mathrm{C}$ previously mentioned). Heating these complexes to higher temperature always gives volatile carbon oxides regardless of the type of carbon material involved; at $1000^{\circ} \mathrm{C}$, there are virtually no surface oxides left. Smith considers that the evidence for the presence of phenol, ketone and quinone groups on the surface requires verification and that there is no direct proof for the existence of lactones. Actually, more evidence on the presence of quinones (but not discussed by Smith) is available from the earlier work of Heller[16] and Wawzonek and Eftax [17].

Lygin et al[81], who obtained evidence for the presence of hydroxyl, carbonyl and carboxyl groups, point out that phenolic and carbonyl groups in proximity to each other, and in a favorable orientation can form hydrogen bonds. This is similar to the interaction of hydroxyl groups with - S SiO- groupings in porous glass and silica gel, and hydrogen bonding between the layer planes of massive carbon.

Although most oxidation reactions involving graphite have been studied at elevated temperatures, Boehm et al [67] found that oxidation of microcrystalline graphite at $400-450^{\circ} \mathrm{C}$ formed acidic surface oxides (or hydroxides in the presence of $\mathrm{H}_{2} \mathrm{O}$ ) at the carbon layer boundaries. Four different types of acidities were detected: strongly acidic, weakly acidic, phenolic and carbonyl. Subsequently, they presented evidence for the existence of these different types[68]. Based on neutralization with bases of increasing acidity, the four groups (shown in Fig. 5) had a neutralization ratio of $1: 2: 3: 4$ for carbon samples oxidized by oxygen at elevated temperatures. With carbons oxidized at room temperature in aqueous solution, the neutralization ratio was $2: 3: 4: 4$. Group 1 , the strongest acids, consists of twice as many carboxyl groups as there are other groups formed by the low temperature oxidation. Group II, which also consists of carboxyl groups but of much weaker acidity, appears to form lactones with adjacent Group IV sites on the carbon edge; Group IV, the weakest acidic group, consists of carbonyl groups, probably aldehydic. Group III was positively identified as being phenolic hydroxyl groups.

Although the relative arrangement of the groups detected by Boehm et al [68] is still somewhat speculative, the schematic formula of Fig. 5 containing all of the detected groups also contains a free radical. The existence of free radicals associated with aromatically bonded oxygen has been postulated by Donnet et al $[82,83]$. Recently, Weinberg and Reddy[84] investigated the electrochemical oxidation of graphite fiber surfaces, using titration of the groups. Since their results could be correlated with those of Boehm, the existence of the different types of acidity seems reasonably well established.

Murphy, et al[85] investigated the surface oxides of electrodes prepared from powdered Norit A charcoal-graphite, using titration methods along with differential thermal, thermogravimetric and infrared analysis in inert atmospheres. Functional groups were found to be $50-65 \%$ earboxyl, $<5 \%$ carbonyl and $0.75-0.77$ mequiv/g phenolic hydroxyl. These groups served as the sites for catalytic reactions, redox reactions (involving phenolic groups) and ion exchange (involving carboxyl groups) when used in purification studies of brackish waters. This work was an extension of investigations[86], which established the mechanism of demineralization and regeneration at

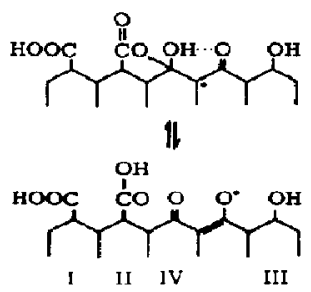

Fig. \$. Acidic organic functional groups detected on graphite surfaces[67]. I and II: carboxyl; III: phenolic hydroxyl; IV: carbonyl. 
chemically treated carbon paste electrodes, where the active sites were carboxylic and phenolic groups.

\section{Quinone-hydroquinone species}

The well known electrochemical redox activity of the quinone and hydroquinone species,

$$
\mathbf{Q}+2 \mathbf{H}^{+}+2 e \rightleftharpoons \mathbf{H}_{2} \mathbf{Q}
$$

has spurred polarographic investigation of surface activity of carhon surfaces in terms of these functionalities. Thus, Hallum and Drushel[87] present evidence for the existence of quinone and aromatic hydroxyl groups on the surface of carbon black, based on polarographic response with varying concentration of a carbon black maintained in the cell as a slurry. In dimethylformamide solution (DMF) containing tetrabutylammonium iodide as background electrolyte, many blacks gave a cathodic wave in the region of the quinone reduction $\left(E_{1 / 2}=-0.69\right.$ to $-0.82 \mathrm{~V}$; all potentials are vs aqueous sce). Some blacks gave an $E_{1 / 2}$ of -1.54 to $-1.63 \mathrm{~V}$, which could be due to reduction of carbonyl group or carboxyl group. $i e$, hydrogen ion reduction, but these possibilities were not investigated.

Possible interference or development of artifact waves by quinone and hydroquinone groups in the carbon blacks was eliminated by first treating the black with 2,2,4-trimethylpentane to rid it of quinone (subsequent potential sweeps showed no quinone wave) and with peroxide-free butadiene to eliminate hydroquinone (the polarographic wave for hydroquinone at $E_{1 / 2}=0.62 \mathrm{~V}$ disappeared). Figure 6 shows the type of groups expected, including those due to hydrogen-bonding; however, since the distance between the carbon plane $(3.55 \AA)$ is too great to permit effective bonding, the $\mathrm{OH}$ groups would probably be more acidic than normal.

Subsequently, Drushel and Hallum[88] utilized coulometry at constant potential to determine the amounts of quinone and hydroquinone groups in carbon blacks. The electrolysis cell medium for reduction was $0.1 \mathrm{M} \mathrm{Et}_{4} \mathrm{NI}$ in DMF; the reference electrode was a silver sheet immersed in $0.1 \mathrm{M} \mathrm{Et}_{4} \mathrm{NI}$ in DMF and separated from the main compartment by a frit (reference to this electrode as an $\mathrm{Ag} / \mathrm{AgI}$

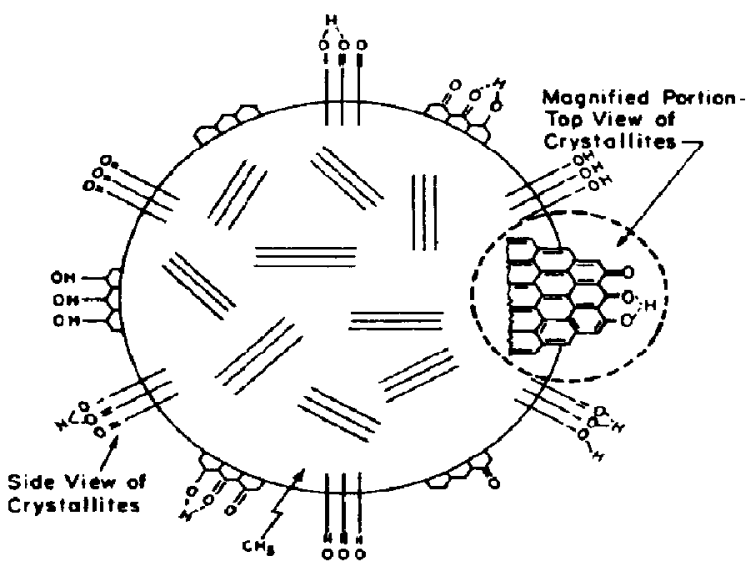

Fig. 6. Model of surface of carbon black particle, showing quinone and aromatic hydroxyl (hydroquinone) groups[87]. electrode is subject to argument). For electrolytic oxidation, the medium was $0.1 \mathrm{M} \mathrm{NaNO}$ in DMF; the reference electrode was $\mathrm{Ag}$ immersed in $0.1 \mathrm{M} \mathrm{Et}_{4} \mathrm{NI}$ in MeOH. Depending on the carbon black used, the quinone content varied from 0.002 to $0.255 \%$ and that of hydroquinone from 0 to $0.344 \%$; on treatment of the carbons, as previously mentioned, the amounts shifted in predictable manner. The observation of anomalous limiting currents, especially after reduction of the carbon with $\mathrm{LiAlH}_{4}$, may be due to an excessively strong attack on aromatic rings of the carbon surface, converting them to more saturated rings.

Recently. Blurton[69], who investigated low porosity carbon electrodes in acidic aqueous electrolytes, proposed that the observed cyclic voltammetric anodic peaks were due to the oxidation of hydroquinonelike groups and that the cathodic peaks were due to the reduction of quinone-like groups. His comments on possible lactone formation under certain conditions when carboxylic groups may be present, emphasize the complexities inherent in any attempt at a complete determination of the surface groups present under all conditions and at comparisons between electrodes. For example, carboxylic groups were detected on a graphite powder electrode, but the history of this electrode must undoubtedly differ from that of the soljd electrode.

\section{Adsorption and surface nature}

Some sections of Smith's review[73], to which reference has been made, are quite pertinent to the present discussion, particularly in regard to the adsorptive properties of carbon which are due to the nature of the surface oxygen complexes, and which are, consequently, strongly influenced by the temperature of carbonization of the starting material. Carbons made at low temperatures $\left(<400^{\circ} \mathrm{C}\right)$ adsorb only base, while those made above $700^{\circ} \mathrm{C}$ are acidadsorbing. On the other hand, carbons heated below $200^{\circ} \mathrm{C}$ in oxygen will adsorb strong acid from solution but not strong base, while those heated in oxygen between $200^{\circ}-750^{\circ} \mathrm{C}$ will only adsorb strong base.

On acid-adsorbing carbons, adsorbability decreases as follows for different adsorbates: non-electrolytes, large ions of organic strong electrolytes, hydrogen ions on oxygen complexes, hydrogen ions on bare carbon, and metal ions, inorganic anions and hydroxy ions. Smith[73] uses the following equilibria to explain the observed adsorption phenomena, where $\left(\mathrm{C}_{x} \mathrm{O}\right)$ is of a quinone nature and the groups in the parentheses indicate surface (carbon-oxygen) species which will have an electrokinetic potential as shown by the signs on the parenthetic entities:

$$
\begin{gathered}
\left(\mathrm{C}_{x} \mathrm{O}\right)+\mathrm{H}^{+}+A^{-} \rightleftharpoons\left(\mathrm{C}_{x} \mathrm{OH}\right)^{+}+A^{-} \\
\left(\mathrm{C}_{x}\right)+\mathrm{H}^{+}+A^{-} \rightleftharpoons\left(\mathrm{C}_{x}\right) \mathrm{H}^{+}+A^{-} \\
\left(\mathrm{C}_{x} \mathrm{O}\right)+\mathrm{II}_{2} \mathrm{O} \rightleftharpoons\left(\mathrm{C}_{x} \mathrm{OH}\right)^{+}+\mathrm{OH}^{-}
\end{gathered}
$$

Reaction 12 is observed only in dilute solutions $(<002 M)$ and shows a one to one relationship between surface oxygen atoms and adsorbed acid. At higher concentrations, this reaction still occurs but is masked by the larger adsorption of reaction 13 . The acid adsorbed by reaction 13 is easily washed out, but that held by reaction 12 can only be removed with $\mathrm{NaOH}$. Reaction 14 explains why aqueous suspensions of these carbons show an alkaline reaction, 
though only weakly so because most of the $\mathrm{OH}^{-}$ions are held in the diffuse double layer.

Base-adsorbing carbons, which show cationexchange properties to some extent, give an acidic aqueous suspension. Adsor bed base cannot be washed out with water, and large amounts of non-electrolytes can be added without affecting the base adsorption. The following reactions, which are considered to explain these observations, involve two types of $\mathrm{C}-\mathrm{O}$ sites [hydroquinonic or phenolic $\left(\mathrm{C}_{x} \mathrm{OH}\right)$ and acid anhydride or fluorescein lactone $\left.\left(\mathrm{C}_{z} \mathrm{O}\right)\right]$ :

$$
\begin{aligned}
\left(\mathrm{C}_{z} \mathrm{O}\right)+\mathrm{H}_{2} \mathrm{O} \rightleftharpoons & \left(\mathrm{C}_{z} \mathrm{O}_{2} \mathrm{H}\right)^{-}+\mathrm{H}^{+} \\
\left(\mathrm{C}_{x} \mathrm{OH}\right)+\mathrm{Na}^{+}+\mathrm{OH}^{-} \rightleftharpoons & \left(\mathrm{C}_{x} \mathrm{O}^{-}\right. \\
& +\mathrm{Na}^{+}+\mathrm{H}_{2} \mathrm{O}
\end{aligned}
$$

The acidity observed is much less than might be expected from the equations because the $\mathrm{H}^{+}$is held in the diffuse double layer.

In connection with brief sections on catalytic activity, electrochemistry of surface carbon-oxygen complexes and role of carbon black in rubber compounding, Smith[73] points out that, although catalytic activity by various types of carbons is well recognized, there is no clear proof that surface carbon-oxygen complexes participate. On the other hand, since maximum activity in the chemical oxidation of many materials (including ferrocyanide ion) is observed with carbons having maximum amounts of surface oxygen sites, it is likely that complexes are involved in the following examples.

Organic compounds catalytically oxidized in aqueous solution include (a) amines, amino acids, anilines, $\mathrm{N}$-substituted anilines and aminophenol; (b) formic, oxalic, malonic and thioglycolic acids, (c) salts of uric and substituted uric acids (in alkaline solution), thiourea and phenylurea, and (d) quinol, allantoin and hexosephorphoric acid. Inorganic substances or ions catalytically oxidized in alkaline solution include $\mathrm{I}^{-}, \mathrm{S}^{-}, \mathrm{SO}_{3}^{-}, \mathrm{NO}_{2}^{-}, \mathrm{SnO}_{2}^{=}, \mathrm{CrO}_{3}^{-3}, \mathrm{AsO}_{3}^{-3}$, $\mathrm{Fe}(\mathrm{CN})_{6}^{-4}$, and $\mathrm{N}_{2} \mathrm{H}_{4}$, and in acid solution $\mathrm{Sn}^{+2}$, $\mathrm{Fe}^{+2}, \mathrm{Hg}_{2}^{+2}, \mathrm{I}^{-}, \mathrm{Fe}(\mathrm{CN})_{6}^{-4}, \mathrm{SO}_{2}$, and $\mathrm{H}_{2} \mathrm{~S}$.

\section{Uses dependent on surface nature}

It should be borne in mind that practically all of the commercial uses of carbon depend on the presence of surface carbon-oxygen groups. For example, Hallum and Drushel[87] postulate that carbon-rubber binding involves the presence of adjacent $-\mathrm{OH}$ and $>\mathrm{C}=\mathrm{O}$ groups on the surface where a hydrogen ion transfers from the hydroxy group to a double bond of the elastomer, leaving a negative charge on the carbon and creating a carbonium ion of the elastomer. This ion may then attack the aromatic ring of the carbon and bind the elastomer to the carbon particle by a $\mathrm{C}-\mathrm{C}$ bond, or it may attack a quinone group and bind the elastomer by a $\mathrm{C}-\mathrm{O}-\mathrm{C}$ bond. An alternative is removal by the quinone group of a hydrogen atom from the most substituted carbon of the elastomer chain, forming a hydroxy group on the carbon particle and creating a free radical of the elastomer. The latter could then attack the aromatic ring to produce a $\mathrm{C}-\mathrm{C}$ bond to the particle by alkylation.

The lubricating properties of graphite are completely changed on heating the latter to $1200^{\circ} \mathrm{C}$ in vacuo to remove oxygen. When the graphite is then loaded at room temperature, there is an enormous increase in friction; only when oxygen or water vapor ( $0.1 \mathrm{~mm}$ pressure or less) is admitted, does the friction decrease. Apparently, the $\mathrm{C}-\mathrm{O}$ complexes reduce the friction between individual crystallites, not between the cleavage planes. The high temperature evacuation, removing oxygen from the crystallites, leaves froc valencies to increase adhesion between adjacent crystallites.

\section{SUMMARY AND CONCLUSIONS}

This section summarizes the basic points concerning the nature of phenomena at the pyrolytic graphite surface and suggests lines of research aimed at determining what the factors involved in these effects are and how to control or to mitigate them.

Essentially seven types of surface effects, including formation of compounds and/or species, are most plausibly involved in the present use of pyrolytic graphite electrodes. To these might be added the static charge effect [12], although it is more in the nature of a purely physical than a chemical phenomenon.

(1) Chemisorbed oxygen may exist by itself or may serve as attractive sites for water molecules.

(2) Tenaciously held water is of importance when the pge is used in nonaqueous solvent systems.

(3) Oxidation compounds including carbonoxygen reaction sites and complexes may be localized at stress regions.

(4) Carbon-oxygen organic surface compounds, including acidic and hasic functionalities such as quinoid, quinhydrone, phenolic, carboxyl, carbonyl, and lactone, are definite possibilities. Additionally, under special conditions, sulfate surface compounds, hydrogen-bonded interlayer groupings and free radicals may also be present.

(5) Mellitic acid derivatives, eg, pyromellitic acid, chloroquinone, pentacarboxylchlorobenzene and similar compounds can be produced under moderately oxidizing conditions.

(6) Lamellar compounds or their residues may be present when graphite electrodes are subjected to strongly oxidizing conditions. Examples of such reactants are bisulfate and other difficultly reducible or oxidizable species.

(7) Surface films, which constitute a broad area, may encompass any of the previously listed effects, as well as some possibly unknown effects peculiar only to the dense structure of pyrolytic graphite.

No single effect appears to account for all of the aberrant phenomena obscrved on pyrolytic graphite electrodes. Further investigations which may shed light on the problem would involve the determination of the "potential of zero charge" on freshly exposed pyrolytic graphite surface[52], the detection and estimation of surface functional groups by infrared reflection spectroscopy as has been done with active carbon [89], the use of low energy electron diffraction and of scanning electron microscopy, and simultaneous application of electrochemical measurements and some of the just enumerated approaches, as appropriate.

Since the handling of graphite electrodes in air will always result in an element of doubt regarding their possible surface contamination, ey, exposure to oxygen and water may spontaneously produce surface 
species, one might consider handling the electrodes only in a vacuum or highly purified drybox atmosphere. By such controls, the ultimate purity of the electrode surfaces might be assued. However, knowledge leading to the delineation of the surface groups and effects on graphite may lead to practices which will allow the routine use of the clectrodes in open, ambient atmosphere systems.

Acknowledgements-We thank the Naval Ordnance Laboratory, Corona, California, for the Fellowship awarded to R.E.P. under the NOLC Education Program and the National Science Foundation for research support given to P.J.E. R.E.P. extends his gratitude to W. C. Spindler, formerly Electrochemistry Branch Head at NOLC, whose encouragement through the years is deeply appreciated. A portion of the cost of this publication was provided by the Naval Ship Research and Development Center, Annapolis, Md.

\section{REFERENCES}

1. P. J. Elving, I. Fried and W. R. Turner, in Polarography, 1964 (Edited by G. J. Hills) pp. 277-97. Macmillan, London (1966).

2 R. N. Adams, Electrochemistry at Solid Flectrodes Dekker, New York (1969).

3. R. N. Adams, Rev. Polarogr. Japan 11. 71 (1963).

4. H. E. Zittel and F. J. Miller, Analyt. Chem. 37, 200 (1965).

5. F. C. Cowlard and J. C. Lewis, J. Materials Sci. 2, 507 (1967).

6. S. Okazaki, Rev. Polarogr. Japan 15, 154 (1968).

7. A. M. Bond, T. A. O'Donnell and R. J. Taylor, Analyt. Chem. 46, 1063 (1974).

8. R. E. Panzer, Nonaqueous Solvent Electrochemistry Navweps Report No. 8813, Naval Ordnance Laboratory, Corona, Calif. (1965).

9. G. Mamantov, D. R. Freeman, F. J. Miller and H. E. Zittel. J. electroanal. Chem. 9. 305 (1965).

10. R. Vignaud, J. Chim. phys. 67, 973 (1970).

11. L. Redey and N. Lohonyai, Ahh. suchs. Akad. Wiss. 49 (5), 97 (1968).

12. R. E. Panzer and P. J. Elving, I. electrochem. Soc. 119, 864 (1972).

13. L. Kekedy, F. Makkay and A. Dragoi, Studia Univ. Victor Babes-Bolyoi, Ser. Chemia 13, 63 (1968).

14. A. L. Beilby, private communication.

15. A. L. Beilby, Bibliography on the Use and Nature of Carbon as an Electrode Material in Electroanalytical Methods, Dept. of Chemistry, Pomona College, Claremont, Calif. (1965).

16. H. H. Heller, Trans. electrochem. Soc. 87, 501 (1945).

17. S. Wawzonek and D. S. P. Eftä, J. electrochem. Soc. 104, 494 (1957).

18. C. E. Plock, Report No. RFP-1221. Dow Chemical Co., Golden, Colo., 1968.

19. B. Lersmacher, H. Lydtin and W. F. Knippenberg, $Z$. Chem. Ing. Tech. 39, 833 (1967).

20. W. N. Reynolds, Physical Properties of Graphite. Elsevier, New York (1968).

21. S. L. Blum and J. Pappis, Pyrographite. Raytheon Corp. (1960).

22. W. S Horton, Proc. Conf. Carbon, (1961) 5, Vol. 2, pp. 23341 (1963).

23. W. J. Coy, J. Am. Ceram. Soc. 45, 223 (1962).

24. L. F. Coffin, J. Am. Ceram. Soc. 47, 473 (1964).

25. A. Tarpinian, J. Am. Ceram. Soc, 47, 532 (1964).

26. P. L. Walker, L. G. Austin and J. J. Tietjen, Carbon 2 (4), 434 (1965)

27. Y. A. Tkach and O. K. Davtyan. J. phys. Chem. (Russ.) 35, 1346 (1961).

28. O. K. Davtyan, J. phys. Chem. (Russ.) 35. 1276 (1961).

29. Y. A. Tkach and $O$. K. Davtyan, $J$. phys. Chem. (Russ.) 36. 1287 (1962).
30. I. M. Kolthoff and N. Tanaka, Analyt. Chem. 26. 632 (1954).

31. J W. Ross and I. Shain, Analyt. Chem. 28, 548 (1956).

32. F. C. Anson and J. J. Lingane, J. Am. chem. Soc. 79, 4901 (1957).

33. J. K. Lee, R. N. Adams and C. E. Bricker, Analytica. chim. Acta 17, 321 (1957).

34. H. A. Laitinen and C. G. Enke, J. electrochem. Soc. 107, 773 (1960).

35. J. S. Mayell and S. H. Langer, I. electrochem. Soc. 111, 438 (1964).

36. F. J. Miller and H. E. Zittel, Analyt. Chem. 35. 1866 (1963).

3\%. W. R. Turner and P. J. Elving, Analyt. Chem. 37, 467 (1965).

38. W. R. Turner and P. J. Elving, J. phys. Chem. 69, 1067 (1965)

39. W. R. Turner and P. J. Elving, Analyt. Chem. 37, 207 (1965).

40. D. L. Smith, D. R. Jamieson and P. J. Elving, Analyt. Chem. 32, 1253 (1960).

41. E. Smith, L. F. Worrel and J. E. Sinsheimer, Analyt. Chem. 35, 58 (1963).

42. G. R Hennig, in Progress in Inorganic: Chemistry, Vol. 1, (Edited by F. A. Cotton) pp. 125-205. Interscience Publishers, New York (1959).

43. M. L. Dzurus and G. R. Hennig, J. chem. Phys. 27 , 275 (1957).

44. J. Besenhard and H. P. Fritz, Z. Naturf. B, 27, (11), 1994 (1972).

45. H. H. Bauer, M. S. Spritzer and P. J. Elving, J. electroanal. Chem. 17, 299 (1968)

46. J. P. Randin and E. Yeager, J. electrochem. Soc. 118, 711 (1971).

47. R. de Levie, Electrochim. Acta 10, 113 (1965).

48. R. de Levie, in Advances in Electrochemistry. and Electrochemical Engineering, Vol. 6, (Edited by $P$. Delahay) pp. 329 97. Interscience Publishers, New York (1969).

49. B. M. Bulygin, Zh. Prikl. Khim. Leningr. 31, 1832 (1958).

50. A. Beilby, W. Brooks and G. L. Lawrence, Analyt. Chem. 36, 22 (1964).

51. P. J. Elving and D. L. Smith, Analyt. Chem. 32, 1849 (1960).

52. T. N. Andersen, J. L. Anderson and H. Eyring, $J$. phys. Chem. 73, 3562 (1969).

53. H. Binder, G. Standstede, A. Kohling and K. Richter, Electrochim. Acta 9, 255 (1964).

54. E. Yeager, P. Krouse and K. V. Rao, Electrochim. Acta 9, 1057 (1964)

55. M. Janes, N. J. Johnson and E. B. Pilcher, J. electrochem. Soc. 102, 474 (1955).

56. B. Wallen and G. Wranglen, Electrochim. Acta 10, 43 (1965).

57. M. M. Fliskii, I. E. Veselovskaya and R. V. Dzhagatspanyan, $Z$ h. Prikl. Khim. Leningr. 33, 1901 (1960).

58. W. A. Nystrom, J. electrochem. Soc. 116, 17 (1969).

59. A. J. Arvia, W. E. Triaca and H. A. Videla, Electrochim. Acta 15, 9 (1970).

60. L. J. J. Janssen and J. G. Hoagland, Electrochim. Acta 14, 1097 (1969)

61. M. O. Davies, M. Clark, E. Yeager and F. Hovorka, J. electrochem Soc. 106, 56 (1959).

62. V. A. Garten and K. Eppinger, Aust. J. Chem. 12, 394 (1959).

63. V. A. Garten and D. E. Weiss, Kev. pure appl. Chem. 7, 69 (1957).

64. J. Bulawa, Przem. Chem. 42, 473 (1963).

65. J. B. Morris and J. M. Schempf, Analyt. Chem. 31, 286 (1959).

66. W. R. Turner and P. J. Elving, $J$. electrochem. Soc. 112,1215 (1965). 
67. H. P. Boehm, E. Diehl, W. Heck and R. Sappok, Angew. Chem. Int. Ed. 3, 669 (1964).

68. H. P. Boehm, E. Diehl, W. Heck and R. Sappok, Angew. Chem. 76, 742 (1964).

69. K. F. Blurton, Electrochim. Acta 18, 869 (1973).

70. B. B. Arnold and G. W. Murphy, J. phys. Chem. 65. 135 (1961).

71. G. J. Janz and D. J. G. Ives, in Reference Electrodes, (Edited by D. G. G. Ives and G. J. Janz.) pp. 270-321. Academic Press, New York (1961).

72. L. Chuang. I. Fried and P. J. Elving, Analyt. Chem. 36, 2426 (1964).

73. R. N. Smith, Q. Ret. 13, 287 (1959).

74. R. V. Culver and H. Watts, Rev. pure appl. Chem. 10, 95 (1960).

75. A. J. Arvia and W. E. Triaca, Electrochim. Acta 11, 975 (1966)

76. M. Levy, Ind. Eng. Chem. Prod. Res. Develop. 1, 19 (1962)

77. M. Levy and P. Wong, J. electrochem. Soc. 111, 1088 (1964).

78. H. Marsh, T. E. O'Hair and W. F. K. Wynne-Jones, Trans. Faraday Soc. 61, 274 (1965).

79. G. R. Hennig, Proc. Conf. Carbon (1959) 4, 145 (1960)
80. G. R. Hennig, Proc. Conf. Carbon (1961) 5, 143 (1962).

81. V. I. Lygin, N. V. Kovaleva, N. N. Kavtradze and A. V. Kiselev, Kolloid. Zh. 22, 334 (1960); Colloid J., N. Y. 22, $345(1960)$.

82. J. B. Donnet and G. Heinrich, Bull. Soc. chim. France $1609(1960)$.

83. J. B. Donnet, G. Heinrich and G. Reiss, Revue gen. Caoutch. 38, 1803 (1961).

84. N. L. Weinberg and T. B. Reddy, J. Appl. Electrochem. 3, $73(1973)$

85. G. W, Murphy, J. L. Cooper, J. A. Hunter, W. S. Gilliam, S. Johnson and R. H. Horowitz (Univ. Oklahoma, Norman). L.S. Office of Saline Water, Res. Devel. Progr. Rept.. No. 399 (1969).

86. S. Evans and $W$. S. Hamilton, J. electrochem. Soc. 113. $1314(1966)$.

87. J. V. Hallum and H. V. Drushel, J. phys. Chem 62, 110 (1958).

88. H. V. Drushel and J. V. Hallum, J. phys. Chem. 62, 1502 (1958).

89. J. S. Mattson, H. B. Mark and W. J. Weber, Analyt. Chem. 41, 355 (1969).

90. G. R. Hennig. J. Chim. phys. 58. 12 (1961). 